\title{
TERMALISMO E HIDROQUÍMICA COMO EVIDÊNCIAS DE LIMITE DE FLUXO REGIO- NAL NO SISTEMA AQUÍFERO GUARANI NO SUL DO BRASIL
}

\author{
THERMALISM AND HYDROCHEMISTRY AS EVIDENCES OF REGIONAL FLOW BOUNDARY IN \\ GUARANI AQUIFER SYSTEM, SOUTHERN BRASIL
}

\author{
Arnoldo Giardin ${ }^{1}$; Ubiratan Faccini ${ }^{2}$
}

\begin{abstract}
RESUMO Limites ao fluxo regional no Sistema Aquífero Guarani (SAG), produzidos por dois lineamentos, denominados Rio das Antas (LRA) e Rio Forqueta (LRF), foram identificados no NE do Rio Grande do Sul, Brasil. Termometria e hidroquímica, foram diagnósticos para a caracterização das barreiras de fluxo. O bloco do SAG a NE dos lineamentos possui águas hiper a hipotermais $\left(46,7^{\circ} \mathrm{C}\right.$ a $\left.28,6^{\circ} \mathrm{C}\right)$ e condutividades elétricas elevadas. Os blocos a sul do LRA e a oeste do LRF apresentam águas frias $\left(19^{\circ} \mathrm{C}\right.$ a $\left.21^{\circ} \mathrm{C}\right)$ e hidroquímica relacionável ao aquífero captado, respectivamente Botucatu e Passo das Tropas. A potenciometria não define as compartimentações produzidas pelos lineamentos. Ao sul do LRA, a distribuição de cargas hidráulicas do SAG sugere existência de fluxo divergente, direcionado aos vales dos Rios das Antas e Caí. A barreira de fluxo representada pelo LRA se deve ao escalonamento de blocos de aquífero em zona de falhas, a hidroestratigrafia sendo constante; enquanto que aquela representada pelo LRF é devida à supressão da Formação Botucatu do registro estratigráfico, as Formações Serra Geral e Santa Maria estando em contato direto. Quando considerados os limites definidos pelos dois lineamentos propostos, são eliminadas as discrepâncias entre as cargas hidráulicas modeladas e observadas ao sul do vale do Rio das Antas.
\end{abstract}

Palavras-chave: Sistema Aquífero Guarani, termometria, condutividade elétrica, lineamento.

\begin{abstract}
Limits to regional flow in Guarani Aquifer System (GAS), produced by two lineaments, named Rio das Antas (RAL) and Rio Forqueta (RFL), had been identified in northeast Rio Grande do Sul State, Brazil. Thermometry and hydrochemistry were decisive criteria to flow barriers identification. The GAS block located northeast from these lineaments presents hot waters $\left(28,6^{\circ} \mathrm{C}\right.$ to $\left.46,7^{\circ} \mathrm{C}\right)$ and higher electric conductivities. To the south of RAL and west of RFL, waters are cold $\left(19^{\circ} \mathrm{C} 21^{\circ} \mathrm{C}\right)$ and have chemical composition related to the exploited aquifer: Botucatu and Passo das Tropas, respectively. Hydraulic gradient can't identify both flow barriers (RAL and RFL). To the south of RAL, hydraulic head distribution suggests existence of divergent flow, directed to Rio das Antas and Rio Caí valleys. RAL flow barrier originated from a horizontal heterogeneity (faulting); whereas the RFL one is vertical: Serra Geral and Santa Maria Formations being in direct contact. Limits defined by RAL and RFL will eliminate discrepancies between modeled and observed hydraulic heads to the south of Rio das Antas valley.
\end{abstract}

Keywords: Guarani Aquifer, thermometry, electric conductivity, lineament

\section{INTRODUÇÃO}

A evolução do conhecimento hidrogeológico tem levado a uma caracterização progressivamente mais detalhada da hidroestratigrafia (FACCINI et al., 1999; GARCIA et al., 1999; FACCINI et al., 2000) e do fluxo da água subterrânea no interior do Sistema Aquífero Guarani - SAG (FACCINI et al., 2003; MACHADO, 2005).

Através da investigação de áreas específicas, objeto de pesquisa para água mineral/termal, integrando dados sedimentológicos, geofísicos, estratigráficos, hidroquímicos e hidrodinâmicos, foram identificados limites para o fluxo regional no SAG, aproximadamente coincidentes com os vales dos Rios das Antas e Forqueta (Figs. 1, 2 e 3), nordeste do RS.

A potenciometria matematicamente definida para o aquífero (ARAÚJO et al., 1995, 1999; CAMPOS, 1999, 2000; CPRM, 2005), com as limitações impostas pelos dados disponíveis, estabelece, no limite sul do SAG situado em território sul-rio-grandense, cargas hidráulicas incompatíveis com as observações de campo. Esta discrepância - a potenciometria dos modelos indicando áreas de artesianismo surgente sabidamente inexistentes - é indicativa da existência de sistemas de fluxo independentes, o que ficou comprovado, na área de estudo.

Duas estruturas - mapeáveis na escala 1: 5.000.000-denominadasLineamentosRiodasAntas (LRA) e Rio Forqueta (LRF), cujos traços no relevo coincidem em parte com os vales dos rios que lhes emprestam os nomes (orientados, respectivamente, segundo os azimutes $065^{\circ}$ e $340^{\circ}$ ) marcam os limites do fluxo proveniente do interior da bacia.

A compartimentação do SAG por estruturas subparalelas ao LRA (aproximadamente orientado segundo o azimute $065^{\circ}$ ) foi observada no município de Estrela-RS (GIARDIN e FACCINI, 2010a, inédito).

\footnotetext{
1 Doutorando em Geologia, Programa de Pós-Graduação em Geologia - UNISINOS. Geólogo da Companhia Riograndense de Saneamento - CORSAN e da Secretaria de Saneamento Habitação e Desenvolvimento Urbano - SEHADUR-RS - arnoldogiardin@hotmail.com - Fone: +55.54.3462-3391

Professor do Programa de Pós-Graduação em Geologia - Universidade do Vale do Rio dos Sinos - UNISINOS ufaccini@unisinos.br-Fone: +55.51.3591-1100/Ramal 1768.
} 
Este lineamento é uma estrutura paralela às Zonas de Falhas Blumenau-Soledade e Lancinha-Cubatão (ZALÁN et al., 1987), podendo ser mapeada em território sul-rio-grandense em uma extensão similar àquelas (Fig. 1).
O LRF aparentemente não corresponde a nenhum dossistemas de falhasreferidosnaliteratura, embora a possibilidade de sua identificação anterior por outro autor não possa ser descartada (Fig.1).

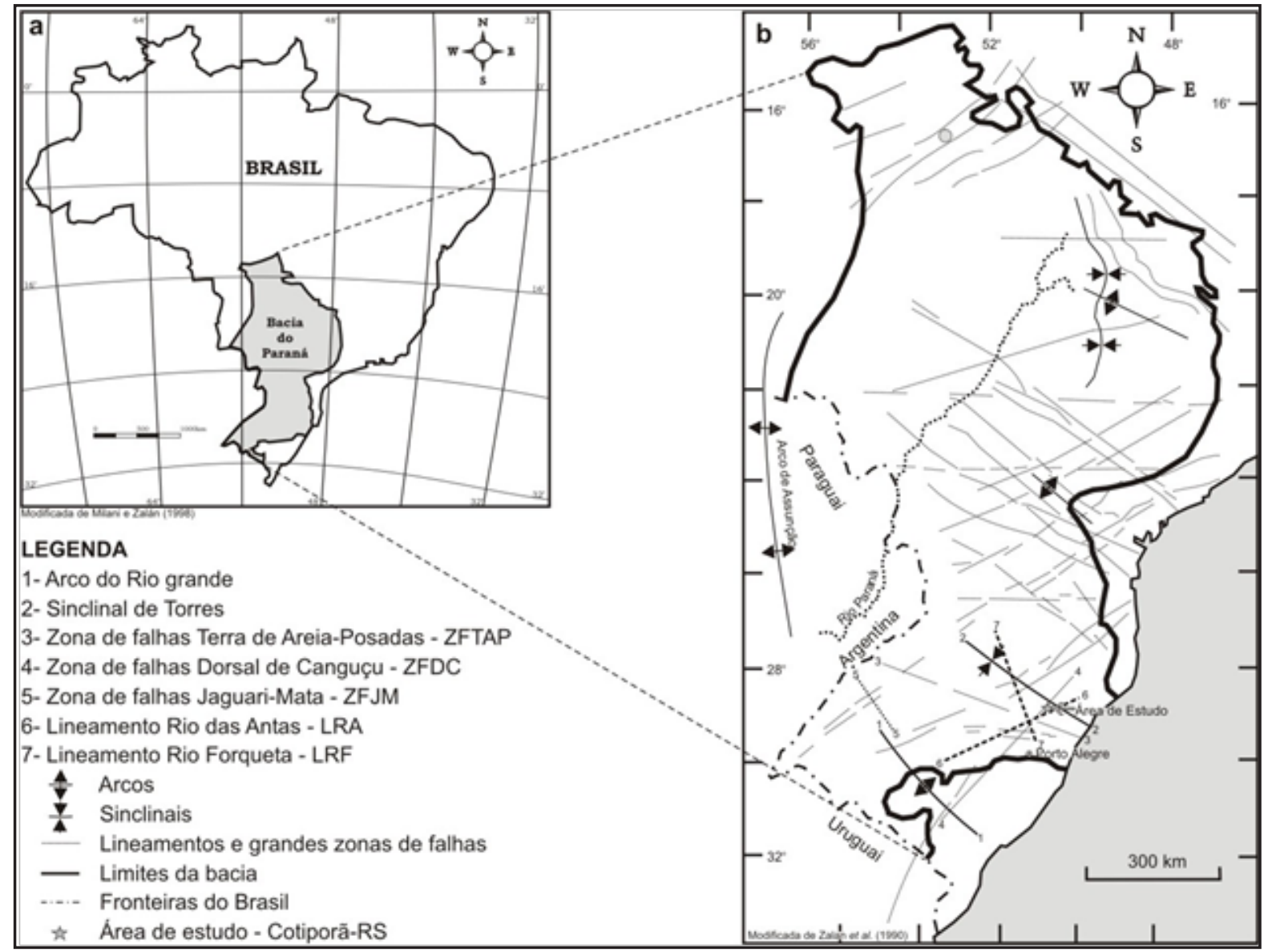

Figura 01- Lineamentos Rio das Antas e Rio Forqueta no contexto estrutural da Bacia do Paraná. Figuras "a" e "b" modificadas, respectivamente de Milani e Zalán (1998) e Zalán et al. (1990)

Figure 01- RAL and RFL lineaments location on Paraná Basil structural framework. Image "a" modified from Milani e Zalán (1998), and "b" from Zalán et al. (1990) 


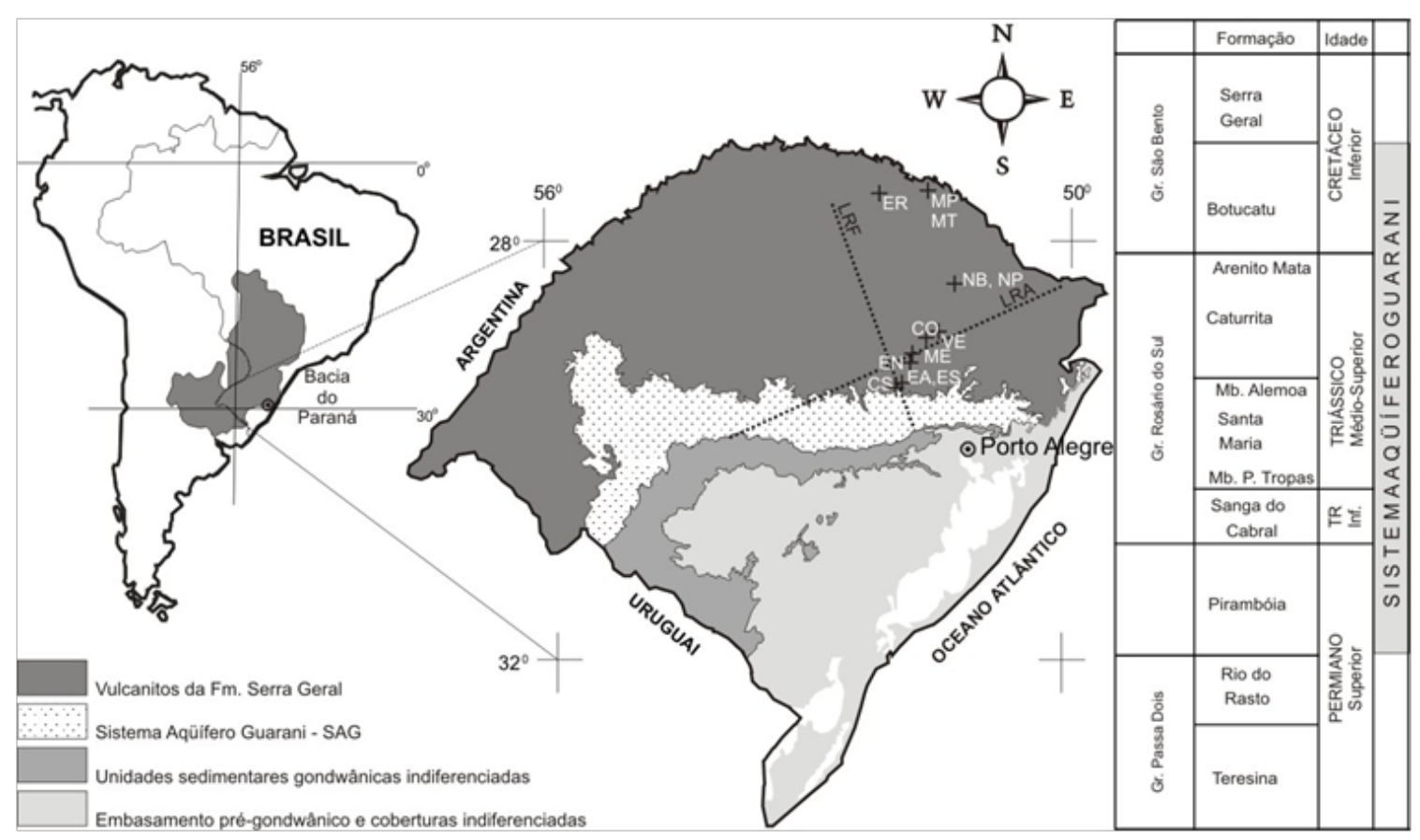

Figura 02- Zonas de falhas, lineamentos e poços sobre mapa geológico simplificado do RS Figure 02- Fault zones, lineaments and water Wells on RS schematic geological map

\section{CONTEXTO GEOLÓGICO}

As unidades litoestratigráficas investigadas neste trabalho pertencem aos grupos Rosário do Sul (Formação Pirambóia) e São Bento (Formação Botucatu), representando registro estratigráfico Permiano Superior até Cretáceo Inferior (Fig. 02).

A Formação Rio do Rasto, do Grupo Passa Dois (Permiano Superior), é o aquiclude que marca a base do SAG.

A Formação Pirambóia (Lavina et al. 1993), correspondendo ao anteriormente denominado conjunto de fácies de sistema eólico úmido da Formação Sanga do Cabral, unidade basal do Grupo Rosário do Sul. De acordo com Faccini et al. (2003), a litofácies que predomina na formação é o conjunto de dunas eólicas, formadas por arenitos com estratificações cruzadas de médio a grande porte, acanaladas e tangenciais, mais raramente planares. A segunda litofácies que compõe a Formação é composta por arenitos tabulares (predominantes) e de pelitos lenticulares. Seu ambiente deposicional foi eólico úmido, conforme comprovado pelas evidências de exposição de seus sedimentos ao freático (Faccini et al., 2003).

A Formação Botucatu ocorre em área superior a $1.300 .000 \mathrm{~km}^{2}$ na bacia do Paraná e a sua área aflorante marca os limites aproximados do SAG. Formada por arenitos quartzosos finos a médios, bimodais e tipicamente apresentando estratificação cruzada de grande porte, possui espessuras que variam de alguns metros no oeste até mais de uma centena de metros na porção Leste de sua faixa de ocorrência no Rio Grande do Sul. O elemento predominante no registro litológico desta Formação é o conjunto de dunas eólicas constituídas por arenitos finos a grossos, bimodais, com estratificação tipicamente cruzada acanalada de grande porte, raramente, planar. O elemento subordinado no registro litológico desta formação é representado por camadas tabulares, horizontalizadas de arenitos finos a médios, classificados como depósitos de interdunas. O ambiente deposicional foi o eólico seco, conforme atestado pela ausência de evidências de influência do freático. A direção predominante de suas paleocorrentes é N-NE (FACCINI et al., 2003).

A estratigrafia do SAG é condicionada pela tectônica no Rio Grande do Sul, sendo possível estabelecer estratigrafia característica para cada um dos três blocos em que se divide sua faixa de exposição. As zonas de falhas Jaguari-Mata e Dorsal de Canguçu sendo as estruturas definidoras desta compartimentação (Figs. 02 e 03).

Outros controles estruturais têm sido identificados para o SAG no Rio Grande do Sul (GIARDIN eFACCINI, 2004; MACHADO, 2005), bem como para suas demais áreas de ocorrência (MONTAÑO et al., 2002; ROSA FILHO et al., 2003). 


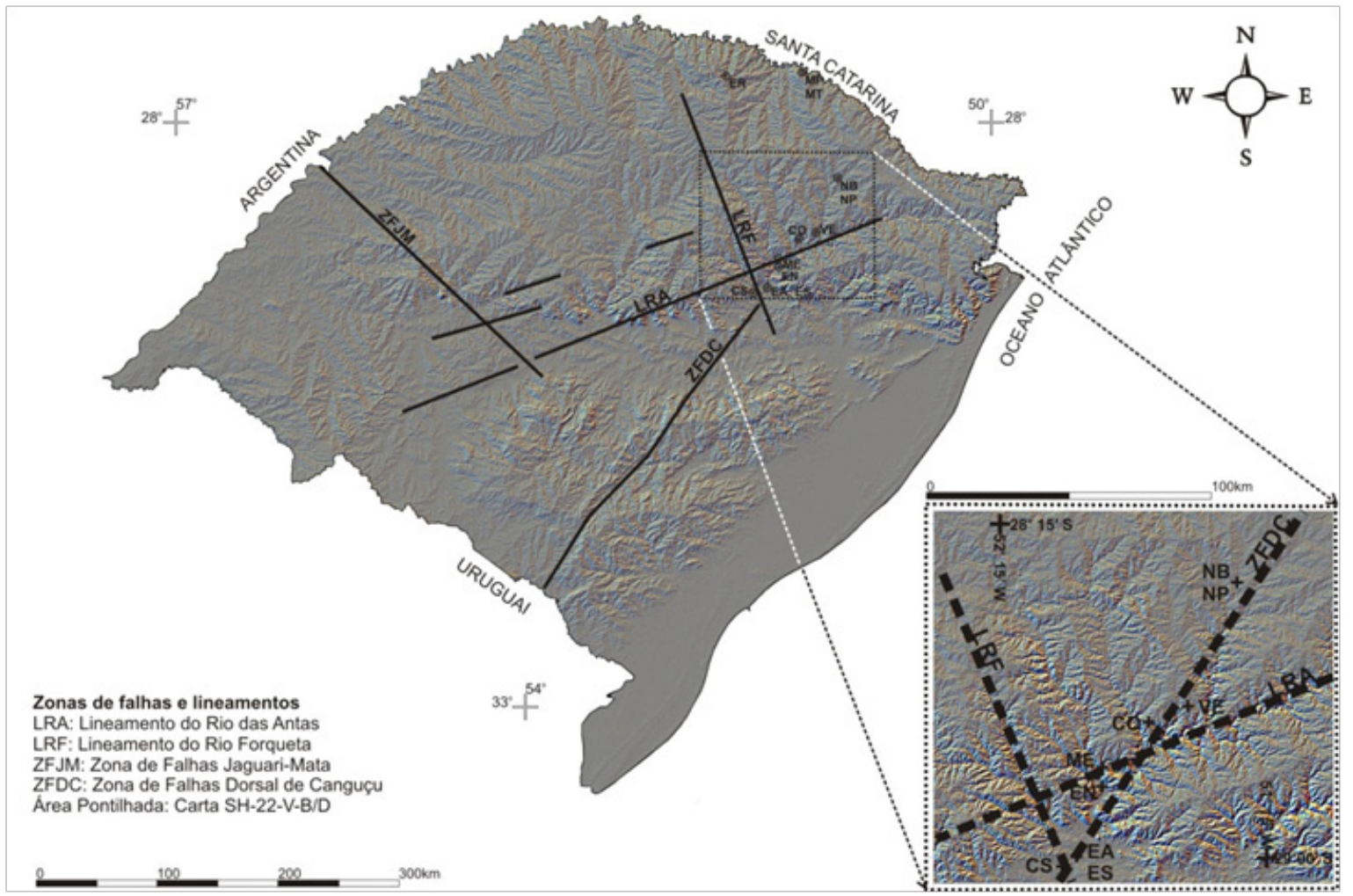

Figura 03- Lineamentos Rio das Antas e Rio Forqueta, Zonas de falhas Dorsal de Canguçu e Jaguari-Mata e localização dos poços sobre MNT filtrado do estado do Rio Grande do Sul

Figure 03- Rio das Antas and Rio Forqueta lineaments, dorsal de Canguçu and Jaguari-Mata fault zones and wells location on filtered Rio Grande do Sul state DEM

\section{ABORDAGEM METODOLÓGICA}

A base metodológica foi adaptada de Huggenberger e Aigner (1999), a abordagem da área sendo feita a partir de sua inserção na bacia, prosseguindo, em escala crescente de detalhamento.

O estudo focou a inserção da área no contexto da bacia e a definição dos limites de seu sistema de fluxo. Detalhamento da arquitetura do aquífero e execução de simulações de fluxo dependem da obtenção de maior volume de dados.

A área de estudo foi inicialmente alvo de levantamentos de campo, com coleta de coordenadas dos poços e das feições hidrogeológicas relevantes, descrições litológicas e identificação de estruturas tectônicas, bem como de seu relacionamento com os campos de poços.

As informações foram inicialmente organizadas em um banco de dados. Mapas hidrogeológicos nas escalas 1:250.000 e 1:500.000 e seções hidrogeológicas em escalas 1:500.000 e 1: 30.000 foram construídos a partir dos perfis litológicos/hidroestratigráficos dos poços considerados (Quadro 1). Os poços MCHRS-01, ERE-19 e 2-AO-1-
RS, perfilados geofisicamente, fundamentaram a aferição de espessuras e porosidades dos Aquíferos Botucatu e Pirambóia, definindo também suas respectivas assinaturas geofísicas (Figs. 4, 5 e 6).

Devido ao porte das estruturas envolvidas, após fotointerpretação inicial, foi montado um Modelo Numérico do Terreno - MNT para todo território sul-rio-grandense (Fig. 02), a partir de 28 modelos numéricos de elevação disponibilizados pela EMBRAPA (MIRANDA, 2005) correspondentes às cartas em escala 1: 250.000 que cobrem o território do Rio Grande do Sul.

Uma seção hidrogeológica, com $185 \mathrm{~km}$ de extensão (Fig. 07), unindo poços situados entre os municípios de Machadinho e Encantado foi construída, para visualizar a superfície potenciométrica e geometria do topo do SAG. A esta seção foi agregado um gráfico com temperaturas e condutividades das águas dos poços representados (Tabela 1).

Uma segunda seção, entre o campo de poços da cidade de Estrela e uma pedreira em Cruzeiro do Sul, com 4,5 km de extensão serviu para mostrar o efeito do Lineamento Rio Forqueta (Fig. 06), conjugado com dois outros sistemas de falhas orientados segundo os azimutes $030-035^{\circ}$ e $310-315^{\circ}$. 
Quadro 01- Poços referidos no texto

\begin{tabular}{|c|l|}
\hline Sigla & \multicolumn{1}{|c|}{ Localização } \\
\hline CO & Áreas de Pesquisa Cotiporã, RS, poços L14J e NSF \\
\hline CS & CORSAN - Poço CSU-01 Cruzeiro do Sul, RS \\
\hline EA & Poço de Água Mineral Estrela, RS \\
\hline EN & CORSAN - Poço ENC-06 Encantado, RS \\
\hline ER & CORSAN - Poço ERE-19 Erechim, RS \\
\hline ES & CORSAN - Poço EST-12b Estrela, RS \\
\hline ME & Poço ELBENN Muçum, RS \\
\hline MP & PETROBRÁS 1-MA-1-RS, Machadinho, RS \\
\hline MT & Terma de Machadinho, RS Poço MCHRS-01 \\
\hline NB & Poço 2-AO-1-RS (Atanásio), Nova Bassano, RS \\
\hline NP & Terma de Nova Prata, RS, Poços SB e AV \\
\hline VE & Poço Usina Velha 03,Veranópolis, RS \\
\hline
\end{tabular}



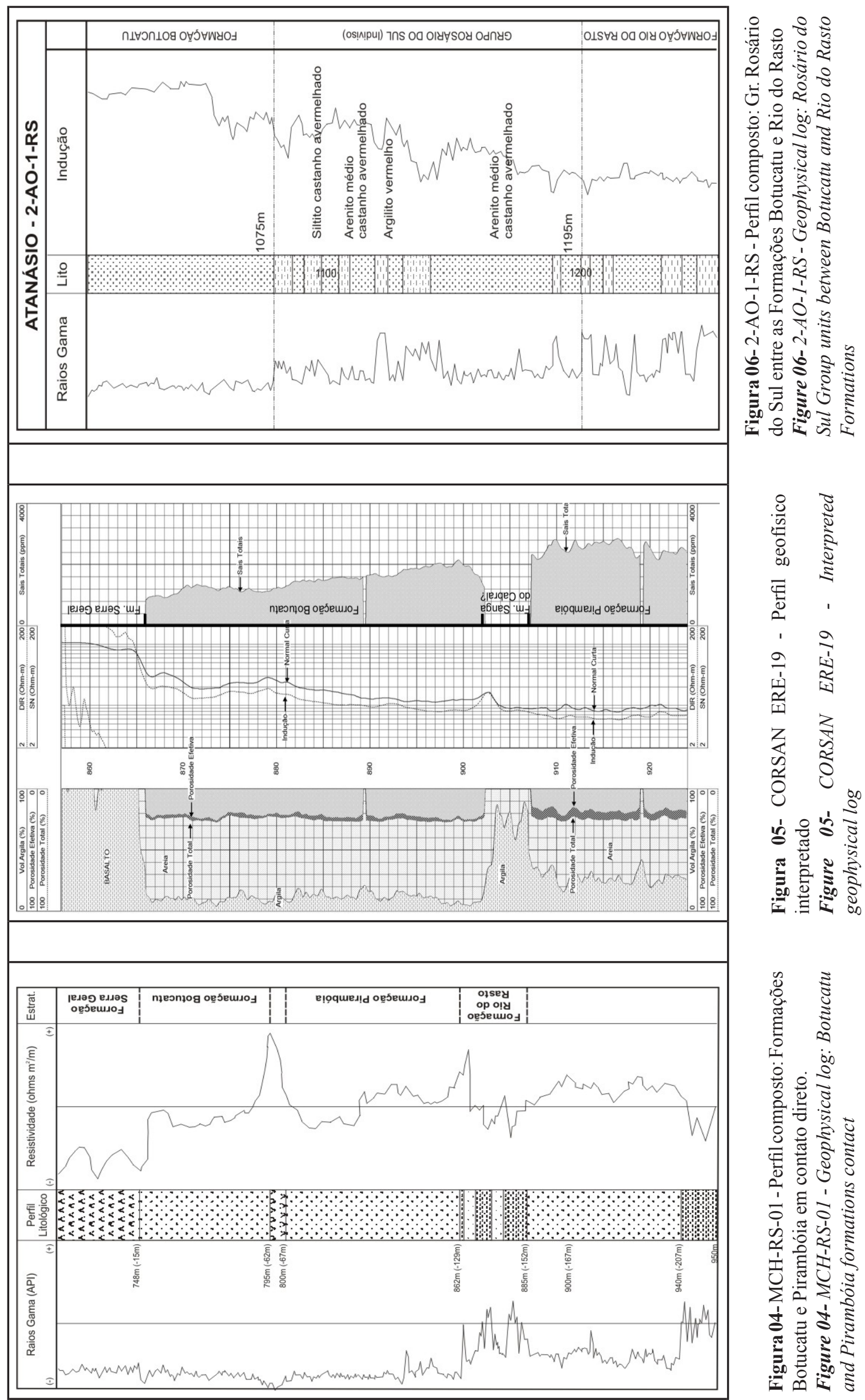
Tabela 1- Parâmetros físicos dos poços selecionados

\begin{tabular}{|c|c|c|c|c|c|}
\hline Poço & $\mathbf{b}_{(\mathbf{m})}$ & $\mathbf{T}_{\left(\mathbf{m}^{2} / \mathbf{s}\right)}$ & $\mathbf{K}_{(\mathbf{m} / \mathbf{s})}$ & Temp. $_{\left({ }^{\circ} \mathbf{C}\right)}$ & Cond. $_{(\mathbf{u S} / \mathbf{c m})}$ \\
\hline CO & $62^{(1)}$ & 0,000681 & 0,000011 & 32,0 & 1450 \\
\hline CS & - & - & - & - & - \\
\hline EA & $15^{(1)}$ & 0,000500 & 0,000033 & 22,0 & 340 \\
\hline EN & $125^{(1)}$ & 0,000647 & 0,000005 & 23,0 & 335 \\
\hline ER & 58 & 0,000778 & $0,000013^{(2)}$ & 38,0 & 1430 \\
\hline ES & $91^{(1)}$ & 0,000647 & 0,000007 & 22,0 & 345 \\
\hline ME & 200 & 0,000420 & 0,000002 & 31,0 & 1380 \\
\hline MP & 109 & 0,000847 & $0,000008^{(2)}$ & 47,3 & 1655 \\
\hline MT & 72 & 0,000375 & $0,000005^{(2)}$ & 46,7 & 1883 \\
\hline NB & 218 & - & - & 44,7 & - \\
\hline NP & $100^{(1)}$ & 0,000264 & 0,000003 & 44,0 & 785 \\
\hline VE & - & - & - & 33,0 & - \\
\hline
\end{tabular}

(1) Penetração parcial no Aquífero Botucatu. (2) Condutividade hidráulica do SAG, considerado como um único aquífero.

\section{HIDROESTRATIGRAFIA E CONDICIONANTES ESTRUTURAIS}

\section{Hidroestratigrafia}

AFormaçãoRiodoRasto,compredominância de pelitos, é o aquiclude na base do SAG.

Os arenitos eólicos permianos da Formação Pirambóia, aquífero basal do SAG, apresentam, na área de estudo, espessuras variáveis entre 24 e $41 \mathrm{~m}$, havendo espessamento em direção ao Sul.

O principal aquífero do SAG na área de estudo é litologicamente representado pelos arenitos eólicos cretáceos da Formação Botucatu, que apresentam espessuras variáveis entre 22 e $84 \mathrm{~m}$ e - como na Formação Pirambóia - são mais espessos em direção ao Sul.

A Formação Serra Geral atua como aquiclude em todas as áreas investigadas, não havendo evidências de recarga do SAG a partir de drenança vertical dos múltiplos aquíferos fraturados desenvolvidos sobre as efusivas da Formação Serra Geral.

A estratigrafia ao norte da área de estudo é compatível com a do bloco Leste da faixa de ocorrência do SAG no Rio Grande do sul, as FormaçõesPirambóiaeBotucatuestandoem contato direto (Figs. 4 e 5) em Machadinho e Erechim.

$\mathrm{O}$ poço Atanásio (2-AO-1-RS) mostra uma estratigrafia mais complexa, com a ocorrência de unidades do Grupo Rosário do Sul.

A hidroestratigrafia imediatamente ao Sul da área de estudo não pôde ser definida, pois os poços deste setor foram parcialmente penetrantes.

\section{Condicionantes estruturais}

Os dois lineamentos, Rio das Antas (LRA) e Rio Forqueta (LRF), com orientação coincidente com os trechos principais dos rios que lhes emprestam os nomes (conferir Figs. 1b e 3), correspondentes a duas zonas de falhas, são os principais condicionantes estruturais da área de estudo. Ambos constituem divisores de fluxo de água subterrânea, variando o mecanismode barreira.

Ao Lineamento Rio das Antas (LRA) não corresponde variação hidroestratigráfica. Fisicamente, ele pode ser identificado pela conformação do topo do SAG (Fig. 07a); termalmente, por marcar o limite entre águas hipotermais e frias (Figura 07b e Tabela 1); hidroquimicamente, por assinalar brusca mudança nos valores de condutividade (Fig. 07b e Tabela 1). Não há variação brusca de carga hidráulica entre os blocos separados por esta estrutura e assim a potenciometria não é diagnóstica para a sua identificação.

O Lineamento Rio Forqueta (LRF) assinala importante mudança hidroestratigráfica: ausência do Aquífero Botucatu. No bloco a oeste deste lineamento, várias perfurações da CORSAN atravessaram - abaixo dos vulcanitos Serra Geral - pacote pelítico com cor avermelhada e espessura de dezenas de metros, antes de penetrar em arenito de granulometria média a grossa, com grânulos de quartzo. Esta sequência estratigráfica, que pode ser vista em afloramento nas imediações de Venâncio Aires-RS bem como em poços neste município e em Estrela-RS, é típica do limite Leste do bloco central do SAG em sua faixa de afloramento no Rio Grande do Sul. A hidroestratigrafia não convencional do 
SAG a Oeste do LRF implica em novo critério de prospecção para a água subterrânea na região, o aquífero-alvo sendo o Passo das Tropas. Este aquífero pode conter água com elevados teores de fluoreto e sulfatos, como ocorre nos poços de Forquetinha; mas pode também conter água potável, caso do poço EST-06 de Estrela, cuja água é empregada para abastecimento público.

Caso as cargas hidráulicas dos aquíferos dos blocos leste e oeste do LRF -Botucatu e Passo das Tropas, respectivamente - não sejam processadas separadamente, a potenciometria não é definidora do divisor de fluxo, pois cargas hidráulicas da ordem de 40 a $60 \mathrm{~m}$ (altitudes) podem ser encontrados nas suas duas margens, à semelhança do apontado por Giardin e Faccini (2004) para a região de Santa Maria, RS. Entre as cidades de Estrela e Cruzeiro do Sul (Fig. 8), a ação deste lineamento e de falhas associadas ao sistema de Falhas Dorsal de Canguçu, separa blocos tectônicos onde o Aquífero Botucatu se apresenta confinado e produtivo ou livre e improdutivo. Entre estes blocos, se encontra um terceiro, onde o Aquífero Botucatu está ausente e os pelitos do Membro Alemoa da Formação Santa Maria estão em contato direto com os vulcanitos da Formação Serra Geral.

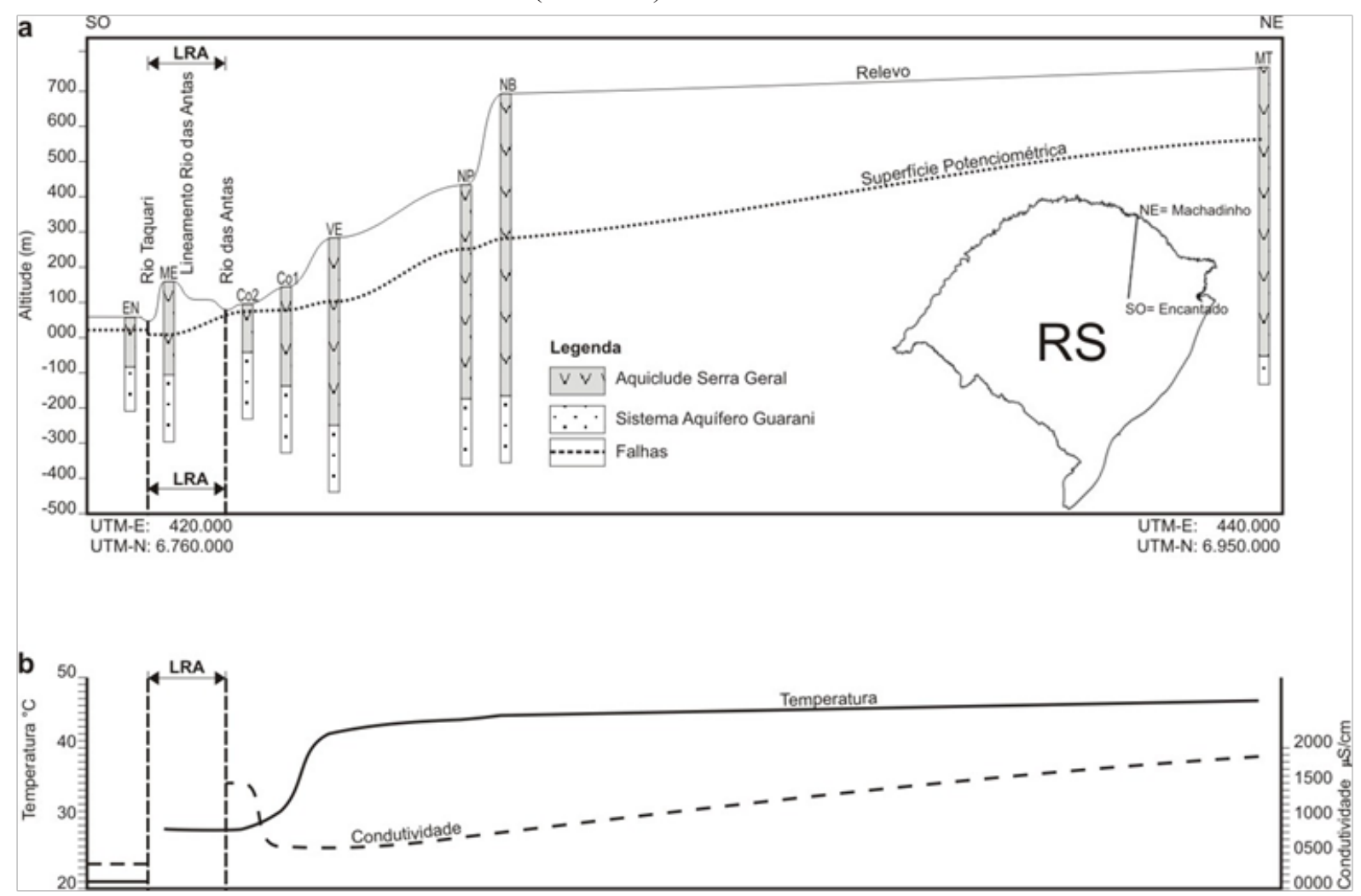

Figura 07- Lineamento Rio das Antas: geometria do topo do SAG e gradiente potenciométrico (a); temperatura e condutividade da água entre as cidades de Machadinho e Encantado (b). O LRA preserva a hidroestratigrafia e não é identificável pela variação potenciométrica. O topo do SAG se apresenta em altitudes maiores em direção ao centro da Bacia do Paraná. Código de Águas Minerais: águas hipotermais com temperaturas entre $25^{\circ} \mathrm{C}$ e $33^{\circ} \mathrm{C}$; águas frias entre $19^{\circ} \mathrm{C}$ e $21^{\circ} \mathrm{C}$.

Figure 07-Rio das Antas lineament: GAS upper boundary geometry and potentiometric gradient (a), temperature and conductivity between Machadinho and Encantado cities (b). RAL doesn't affect hydrostratigraphy and can't be identified by significant hydraulic head change. SAG's top elevations are higher towards Paraná Basin center. According to Brazilian Mineral Water Law, hypothermal waters have temperatures between $25^{\circ} \mathrm{C}$ to $33^{\circ} \mathrm{C}$ and cold waters between $19^{\circ} \mathrm{C}$ to $21^{\circ} \mathrm{C}$. 


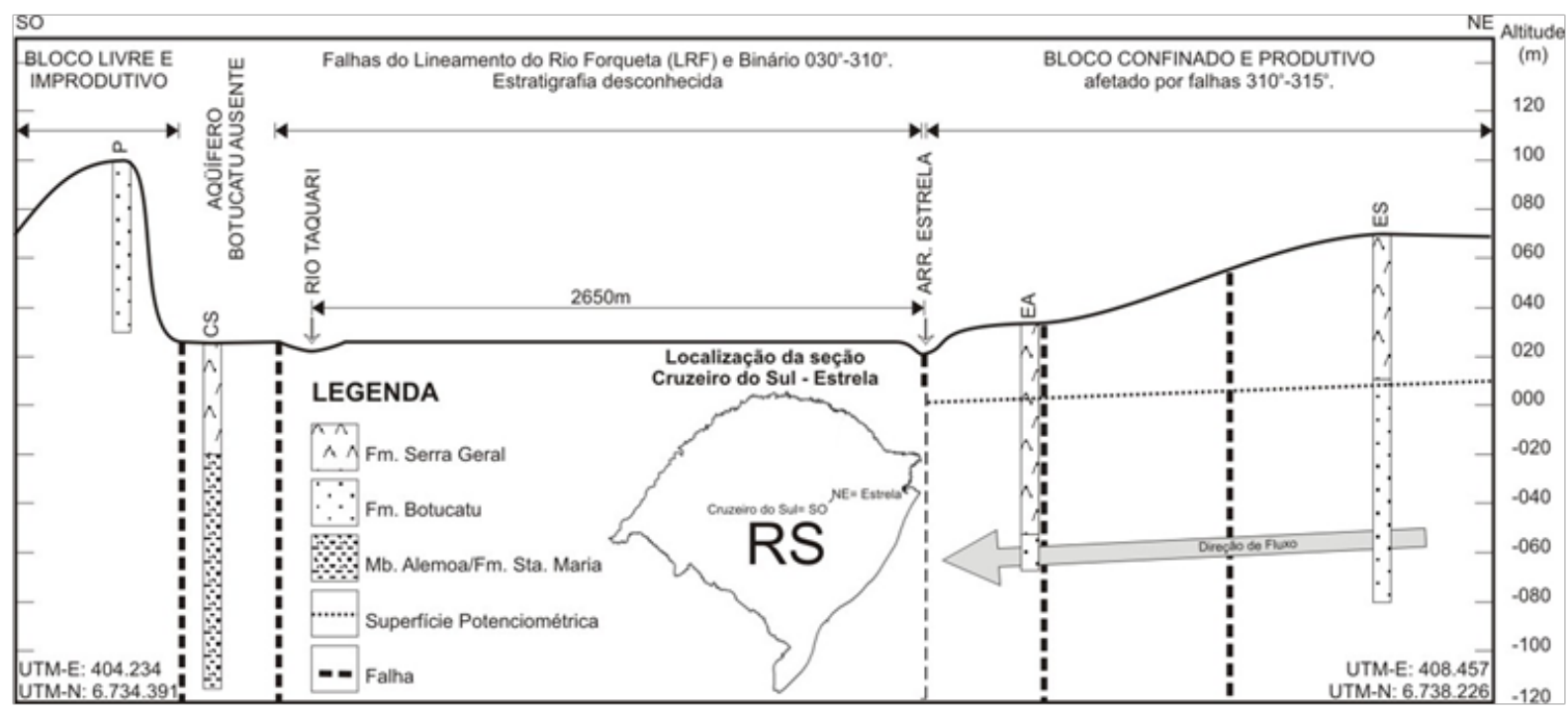

Figura 08- Lineamento do Rio Forqueta: relaciona-se com a supressão do Aquífero Botucatu (bloco contendo o poço CSU-01) e suas condições de confinamento e produtividade. Modificado de Giardin e Faccini (2010a, inédito)

Figure 08-Rio Forqueta lineament: it is related to Botucatu Aquifer suppression and with its productivity and confinement characteristics. Modified from Giardin e Faccini (2010a, unpublished)

A presença do Aquífero Passo das Tropas em profundidade, com base em sua ocorrência ma porção NW da cidade de Estrela, embora não confirmada, é muito provável neste bloco, o que implica reavaliar o potencial de extração de água subterrânea nesta área.

\section{HIDROGEOLOGIA}

\section{Aquíferos}

\section{Aquífero Pirambóia}

Acontribuição deste aquíferopara a produção dos poços que o atravessam não foi estabelecida.

As porosidades total e efetiva estimadas para este aquífero através de geofísica de poço (poços MCH-RS-01 e ERE-19; Figuras 04 e 05) variaram, respectivamente, entre 17 e $24 \%$ e 13 e $17 \%$.

Os sais totais apresentaram ampla gama de variação: em Erechim, do topo para a base, variando entre $2400 \mathrm{mg} / \mathrm{L}$ e $2800 \mathrm{mg} / \mathrm{L}$ (Fig. 5); enquanto que em Machadinho, ao longo de toda espessura do aquífero, este parâmetro mostrou valor aproximadamente constante de $1200 \mathrm{mg} / \mathrm{L}$ (Fig. 4).

Os valores de porosidade estimados para este aquífero são compatíveis com as observações de campo e petrográficas que mostram presença significativa de argila na matriz de seus arenitos (com origem possível na alteração dos feldspatos do arcabouço). Parte dos sais totais deve derivar da mobilização de íons a partir desta matriz.

A espessura do Aquífero Pirambóia é de $24 \mathrm{~m}$ em Erechim, 35m em Machadinho e pode alcançar $44 \mathrm{~m}$ em Nova Prata (poço Ata- násio). No vale do Rio dos Sinos, o Aquífero mostra espessura de 70m (GIARDIN, 2006).

\section{Aquífero Botucatu}

Os valores estabelecidos pela geofísica (poços MCH-RS-01 e ERE-19; Figuras 04 e 05) para as porosidades total e efetiva deste aquífero variaram, respectivamente, entre 20 e $26 \%$ e 15 e $24 \%$, sendo consistentemente mais elevados do que os do Aquífero Pirambóia.

As observações de campo e petrográficas, que informam arcabouço quartzoso e ausência de argila namatrizdosarenitosBotucatu, sãocompatíveiscom os valores de porosidade estimados pela geofísica.

Como no Aquífero Pirambóia, os sais totais calculados pela geofísica de poço em Erechim e Machadinho apresentaram grande variação: em Erechim (do topo para a base) entre 800 $\mathrm{mg} / \mathrm{L}$ e $2000 \mathrm{mg} / \mathrm{L}$ (Fig. 5), enquanto que em Machadinho os sais totais calculados mostraram valor constante aproximado de $800 \mathrm{mg} / \mathrm{L}$ (Fig 4).

$\mathrm{O}$ teor de sais totais é mais elevado, para ambos aquíferos, em Erechim, o que indica a possibilidade de serem derivados de dissolução de minerais em zonas de falhas. AespessuradoBotucatuéde $34 \mathrm{memErechim}$ (ERE-19),37m em Machadinho(MCH-RS-01), podendo alcançar 187m em Nova Prata (2-AO-1-RS).

\section{Parâmetros hidrodinâmicos}

As transmissividades estimadas para o SAG variaram entre $2,8 \mathrm{~m}^{2} / \mathrm{h}$ e $1,35 \mathrm{~m}^{2} / \mathrm{h}$, correspondendo a condutividades hidráulicas entre $0,019 \mathrm{~m} / \mathrm{h}$ e $0,048 \mathrm{~m} / \mathrm{h}$ (tabela 01 ). 
Embora a espessura do SAG seja menor no poço de Erechim do que no de Machadinho, o primeiro apresenta potencial produtivo superior, pois não foi afetado por intrusões de diabásio como ocorreu em Machadinho (MCH-RS-01) que segmentaram o aquífero e degradaram sua condutividade hidráulica (Fig. 4).

Os valores de condutividade hidráulica dos poços parcialmente penetrantes (Tabela 01) devem ser tomados apenas como aproximações, devido à ausência de controle estratigráfico. As espessuras de aquífero empregadas nos cálculos de $\mathrm{K}$ foram de $187 \mathrm{~m}$ (2-AO-1-RS na Figura 6) para os poços ao norte do LRA e $74 \mathrm{~m}$ para aqueles ao sul (GIARDIN, 2001).

\section{Aquicludes}

$\mathrm{Na}$ área investigada, os vulcanitos da Formação Serra Geral, com espessuras variáveis entre $810 \mathrm{~m}$ (MCH-RS-01) e 135m (L14J-01) atuam como aquiclude de topo do SAG e a Formação Rio do Rasto representa o aquiclude basal.

Os pelitos do Membro Alemoa da Formação Santa Maria constituem aquiclude sob o qual se encontra o Aquífero Passo das Tropas (Fig. 2).

Critérios estratigráficos e geofísicos devem ser empregados na diferenciação dos pelitos Rio do Rasto e Alemoa. Os sedimentitos triássicos indicam a possível existência do Aquífero Passo das Tropas em profundidade, enquanto que os permianos constituem o aquiclude basal do SAG.

\section{CONCLUSÕES}

Evidências termométricas e hidroquímicas no Sistema Aquífero Guarani permitiram a identificação de barreiras de fluxo não evidenciadas pela análise potenciométrica. Estas barreiras correspondem fisicamente a dois grandes lineamentos, produzidos por zonas de falhas que limitam o fluxo nos aquíferos devido ao escalonamento de blocos (LRA) ou a uma conjugação de escalonamento com variação estratigráfica (LRF).

Ao Lineamento Rio das Antas corresponde uma barreira de fluxo devido a escalonamento de blocos do aquífero.

A barreira de fluxo produzida pelo Lineamento Rio Forqueta tem natureza tectônica e estratigráfica, a Formação Botucatu estando ausente no bloco situado a Oeste dela.

Mesmo com pequeno espaçamento dos pontos de medida de cargas hidráulicas, a análise potenciométrica, quando empregada isoladamente, não identifica, nas áreas investigadas, os limites dos sistemas de fluxo separados pelos lineamentos Rio das Antas e Rio Forqueta. No caso do LRA o Aquífero Botucatu não mostrou variação perceptível de carga hidráulica nas porções a NO e a SE do lineamento, sendo possível alinhar as cargas hidráulicas disponíveis segundo uma superfície potenciométrica com gradiente hidráulico aproximadamente constante.

Termometria e hidroquímica identificaram barreira de fluxo representada pelo Lineamento Rio das Antas. Hidroestratigrafia e termometria foram os critérios definidores dos limites de fluxo impostos pelo Lineamento Rio Forqueta.

A integração de dados com diferentes qualidades e origens, no contexto da análise hidroestratigráfica, base da metodologia adotada, foi base para a identificação, na escala operacional, de barreiras de fluxo - às quais não correspondem variações potenciométricas significativas - que conciliam o modelo regional de fluxo do SAG (CPRM, 2005) com as cargas hidráulicas observadas em sua extremidade sul.

\section{REFERÊNCIAS}

ARAÚJO, L.M.; FRANÇA, A.B.; POTTER, P.E. Aquífero Gigante do Mercosul no Brasil, Argentina, Paraguai e Uruguai: mapas hidrogeológicos das formações Botucatu, Pirambóia, Rosário do Sul, Buena Vista, Misiones e Tacuarembó. Curitiba, 1995. 16 f. (Hidrogeologia) - UFPR.

ARAÚJO, L.M.; FRANÇA, A.B.; POTTER, P.E. Hydrogeology of the Mercosul aquifer system in the Paraná and Chaco-Paraná Basins, South America, and comparison with the NavajoNugget aquifer system, USA. Hydrogeology Journal , v. 7, p. 317-336, 1999.

CAMPOS, H.C.N.S. Modelación conceptual y matemática del Acuífero Guaraní, Cono Sur - Mapa Hidrogeológico do Aquífero Guarani. Acta Geológica Leopoldensia, São Leopoldo, v. 23, n. 4, p. 3-50, 1999.

CAMPOS H.C.N.S. Modelación Conceptual y Matemática del Acuífero Guaraní, Cono Sur. Mapa Hidrogeológico del Acuífero Guaraní. Escala 1:2.500.000. Acta Geológica Leopoldensia, São Leopoldo, v. 4, p. 51, 2000.

\footnotetext{
CPRM-COMPANHIA DE PESQUISA DE RECURSOS MINERAIS. Mapa Hidrogeológico do Rio Grande do Sul $\square$ Porto Alegre-RS: CPRM, 2005. 1: 750000.
} 
FACCINI, U.F. Estratigrafia do Permo-Triássico do Rio Grande do Sul: estilos deposicionais versus espaço de acomodação. Porto AlegreRS, 2000. 322 f. Tese de Doutorado - PPGEOUFRGS, UFRGS.

FACCINI, U.F.; GARCIA, A.J.V.; LAVINA, E.L.C.; SUSZCZYNSKI, A.M.; ZERFASS, H. Geometry, architecture and porosity distribution in Triassic sandstones in southern Paraná Basin, Brazil: porous aquifer potential in Mercosul context. In: REUNIÃO ANUAL DA SBPC, 51., 1999, Porto Alegre-RS. Anais. Porto Alegre-RS: SBPC, 1999.

FACCINI, U.F.; LAVINA, E.L.; LOPES, R.C.; SCHULTZ, C.L.; DUTRA, T.G.D. Gondwana sequences (Early Permian to Early Cretaceous) in Southern Border of Paraná Basin - stratigraphy and paleontology (Rio Grande do Sul State, Southern Brazil). In: INTERNATIONAL GEOLOGICAL CONGRESS, 31., 2000, Rio de Janeiro. Anais. Rio de Janeiro: SBG-IUGS, 2000. p. 0-37.

FACCINI, U.F.; GIARDIN, A.; MACHADO, J.L.F. Heterogeneidades litofaciológicas e hidroestratigrafia do Sistema Aquífero Guarani na região central do estado do Rio Grande do Sul, Brasil. in: PAIM, P.S.G; FACCINI, U.F.; NETTO, R.G. (Ed.). Geometria, arquitetura e heterogeneidades de corpos sedimentares. 1 ed. São Leopoldo: UNISINOS, 2003. Cap. 3.1. p. $147-173$.

GARCIA, A.J.V.; FACCINI, U.F.; LAVINA, E.L.C.; ZERFASS, H.; SUSZCZYNSKI, A.M. Geometry, architecture and porosity distribution in Mesozoic sandstones in Southern Paraná Basin, Brazil: reservoir/ aquifer potential in Mercosul context. In: GEOLOGICAL SOCIETY OF AMERICA ANNUAL MEETING, P124., 1999, DenverCO-USA. Annals. Denver-CO-USA: Geological Society of America, 1999.

GIARDIN, A. Plano de monitoramento para poço de extração de água mineral. Porto Alegre: Natureza Líquida Ltda., 2001. 21 p.

GIARDIN, A. Relatório final de pesquisa para água mineral - DNPM 810584/2005 Porto Alegre: Natureza Líquida Ltda., 2006. 91 p. 8 anexos.

GIARDIN, A.; FACCINI, U.F. Complexidade hidroestratigráfica e estrutural do Sistema Aquífero Guarani na região central do Rio Grande do Sul: abordagem metodológica aplicada ao exemplo da área de Santa Maria RS, Brasil $\square$ Revista Águas Subterrâneas, São Paulo, n. 18, p. 39-54, 2004.

GIARDIN, A.; FACCINI, U.F. Identificação de Células de Fluxo Local no Sistema Aquífero Guarani na Área de Influência da Zona de Falhas Dorsal de Canguçu - Estudo de Caso no Vale do Rio Taquari-RS, Brasil.. Artigo em elaboração, 2010a.

HUGGENBERGER, P.; AIGNER, T. Introduction tom the special issue on aquifersedimentology: problems, perspectives and modern approaches. Sedimentary Geology, Amsterdam, v. 129, n. 3, p. 179186, 1999.

LAVINA E.L.C.; FACCINI, U.F.; RIBEIRO, H.J.S. A Formação Pirambóia (PermoTriássico) no Estado do Rio Grande do Sul. Acta Geológica Leopoldensia, São Leopoldo, v. XVI, n. 38, p. 179-197, 1993.

MACHADO, J.L.F. Compartimentação Espacial e Arcabouço Hidroestratigráfico do Sistema Aquífero Guarani no Rio Grande do Sul. São Leopoldo, 2005. 238 f. Tese de Doutoramento - PPGEO/UNISINOS, UNISINOS.

MILANI, E.J.; ZALÁN, P.V. Brazilian Geology Part 1: the Geology of Paleozoic Cratonic Basins and Mesozoic Interior Rifts of Brazil. In: RIO'98 AAPG INTERNATIONAL CONFERENCE AND EXHIBITION, 1., 1998, Rio de Janeiro, RJ, Brasil. Short Course Notes. Rio de Janeiro: AAPG/ABGP, 1998.

MIRANDA, E. E. DE (COORD.). Brasil em Relevo. Rio de Janeiro: EMBRAPA, 2005. Disponível em: <:http://www.relevobr.cnpm. embrapa.br> Acesso em: 23 mai. 2006.

MONTAÑO J.; ROSA Fo. E.F.; HINDI E.C.; CICALESE-MONTAÑO M.; URTASUN S.G. Importância de las estructuras geológicas em el modelo conceptual del Sistema Acuífero Guarani - Área Uruguaya. Revista Águas Subterrâneas, São Paulo, v. 16, p. 111-119, 2002.

ROSA FILHO, E.F.; HINDI, E.C.; ROSTIROLLA, S.P.; FERREIRA,F.J.F.;BITTENCOURT,A.V. L. Sistema Aquífero Guarani - considerações preliminares sobre a influência do Arco de Ponta Grossa no fluxo das águas subterrâneas. Revista Águas Subterrâneas, São Paulo, v. 17, p. 91-111, 2003.

ZÁLAN P. V., WOLLF S., CONCEIÇÃO J. C. J., ASTOLFI, M.A.M., VIEIRA, I.S. Tectônica e Sedimentação da Bacia do Paraná. In: Simpósio Sul-Brasileiro de Geologia, 3., 1987, Curitiba. Atas... Porto Alegre: Sociedade Brasileira de Geologia, 1987. v.1. p. 441-477.

ZÁlAN P. V., WOLLF S., VIEIRA E. S., CONCEIÇÃ̈O J. C. J., APPI V. T., NETO E. V. S., CERQUEIRA J. R. E MARQUES A. 1990. The Paraná Basin. In: Leighton M. W., Kolata D. R., Oltz D. F., Eidel J. J. (Eds). 
M. W., Kolata D. R., Oltz D. F., Eidel J. J. (Eds). suporte financeiro a este trabalho (Projeto Interior Cratonic Basins. AAPG Memoir Universal 485983/2007-9 e Bolsa de Pesquisa 51:681-708.

\section{AGRADECIMENTOS}

Os autores agradecem ao CNPQ pelo (Processo 309475/2007-4) e à CORSAN pela disponibilização de dados e auxílio financeiro e aos revisores anônimos, cujas críticas e sugestões aperfeiçoaramemmuitoaversãofinaldeste trabalho. 